\title{
ANALISIS KELENGKAPAN PENGISIAN REKAM MEDIS ELEKTRONIK RAWAT INAP GUNA MENINGKATKAN MUTU PELAYANAN DI RS X BANDUNG
}

\author{
Firly Oktavia Lestari ${ }^{1 *}$, Ai Ainun Nur'aeni' ${ }^{2}$, Dina Sonia ${ }^{3}$ \\ Politeknik Piksi Ganesha Bandung, Indonesia ${ }^{1,2,3}$ \\ firlyokt10810@gmail.com ${ }^{1 *}$, ainunnuraeni29@gmai.com², nasoniaonya.ds@gmail.com ${ }^{3}$
}

Received: 07-09-2021

Revised : 22-10-2021

Accepted: 23-10-2021

\begin{abstract}
Abstrak
Latar Belakang: Rumah sakit sebagai sarana pemberi pelayanan kesehatan memiliki peran penting terhadap derajat kesehatan, dituntut untuk mampu memberikan pelayanan yang optimal. Indikator yang menunjang kualitas pelayanan rumah sakit adalah kekonsistenan pencatatan rekam medis yang dilakukan oleh dokter dan perawat. Kelengkapan rekam medis elektronik sangat penting untuk proses administrasi guna menunjang peningkatan mutu pelayanan yang diberikan rumah sakit.
\end{abstract}

Tujuan: Penelitian ini bertujuan untuk mengetahui jika terdapat pengaruh dalam pengisian rekam medis elektronik terhadap kualitas pelayanan yang dilakukan rumah sakit.

Metode: Penelitian ini menggunakan metode kuantitatif dengan pendekatan deskriptif dibantu dengan Chi-Square. Sebanyak 93 rekam medis elektronik rawat inap di RS X Bandung yang digunakan dalam penelitian ini pengambilan sampel menggunakan teknik Simple Random Sampling.

Hasil: Ketidaklengkapan rekam medis elektronik 33,3\% dan sebanyak $66,6 \%$ pengisian rekam medis elektronik lengkap, berdasarkan hasil tersebut belum memenuhi standar permenkes. Hasil dari Uji Chi-Square berdasarkan kekonsistenan pencatatan pada CPPT, diagnosa, asesmen medis, asesmen keperawatan memiliki nilai $\mathrm{p}=0,001$ dan pada e-resep $\mathrm{p}=0,013$.

Kesimpulan: Maka dapat disimpulkan bahwa Ho ditolak dan Ha diterima artinya terdapat hubungan kelengkapan pencatatan dengan kualitas rekam medis elektronik terhadap pelayanan yang diberikan rumah sakit.

Kata kunci: dokumen rekam medis; kualitas pelayanan; rumah sakit.

\begin{abstract}
Background: Hospitals as a means of providing health services have an important role in health status, they are required to be able to provide optimal services. An indicator that supports the quality of hospital services is the consistency of recording medical records carried out by doctors and nurses. The completeness of electronic medical records is very important for the administrative process to
\end{abstract}




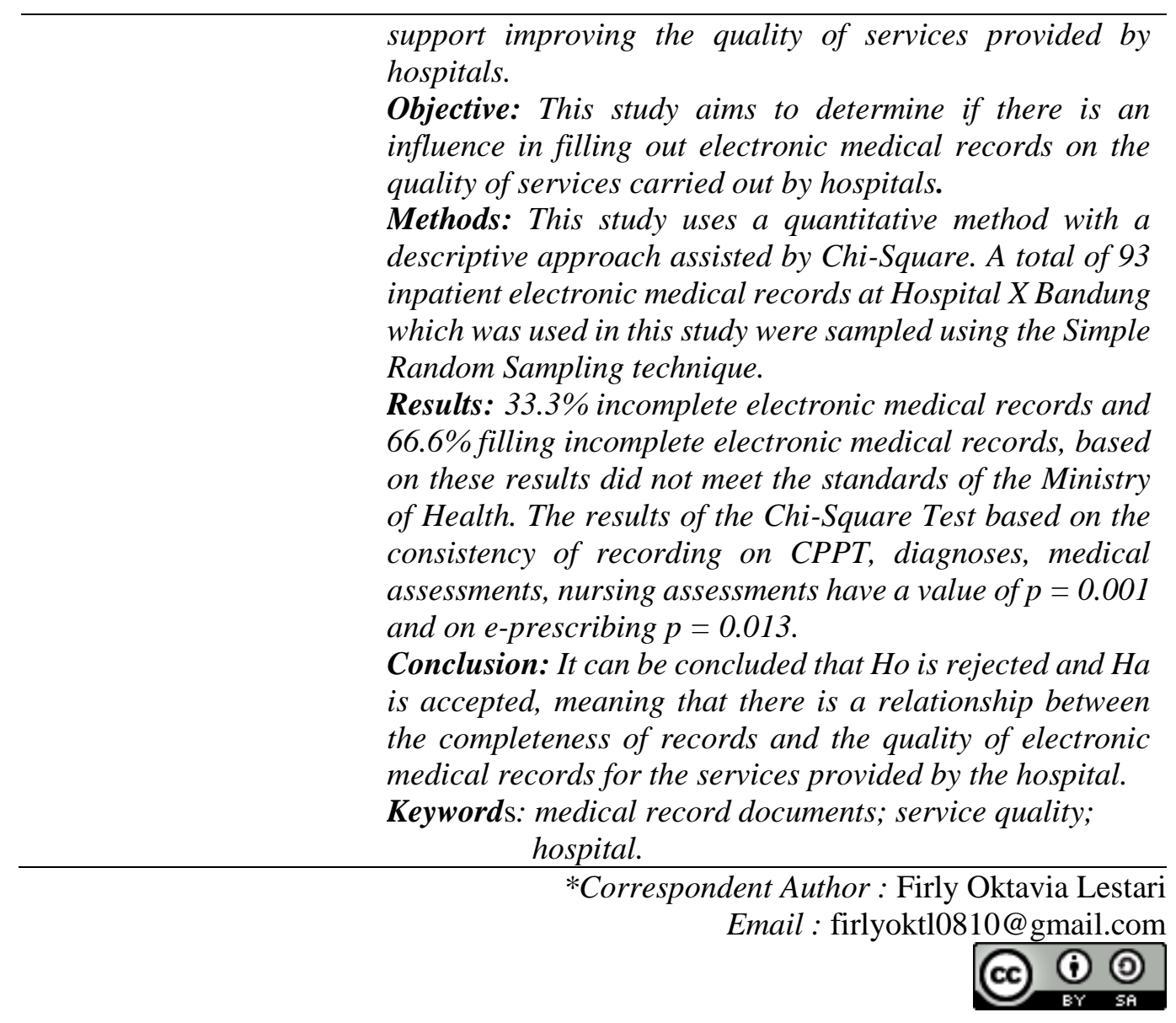

\section{PENDAHULUAN}

Semakin pesatnya kemajuan teknologi di era globalisasi masa kini pada bidang kesehatan terutama dibagian unit rekam medis, rumah sakit diharuskan mengikuti perkembangan teknologi modern dalam penyelenggarakan pelayanan, mendorong rumah sakit di negara-negara berkembang termasuk di Indonesia mulai menerapkan penggunaan Rekam Medis Elektronik atau Electronic Medical Record (EMR) sebagai pengganti rekam medis berbasis kertas menggikuti negara-negara maju yang telah terlebih dahulu menggunakannya (Pratama \& Darnoto, 2017).

Rumah sakit diharapkan dapat memberikan pelayanan kesehatan dengan cepat sehingga dapat mengefektifkan waktu, menjaga mutu pelayanan dengan keakuratan pencatatan EMR dan pelayanan administrasi yang lebih tertata. Disamping sering terjadi kendala dalam penggunaan EMR namun terdapat banyak manfaat bagi rumah sakit dalam penggunaanya apalagi pada saat ini berbagai instansi kesehatan sedang disibukkan oleh lonjakan pasien dengan berbagai penyakit menular. Rumah sakit juga harus senantiasa meningkatkan mutu pelayanan yang sesuai dengan harapan konsumen melalui peningkatan kualitas kerja. Mutu pelayanan sangat penting untuk tetap dapat menjaga keberadaan suatu rumah sakit (Lubis, 2009). Baik buruknya suatu pelayanan digambarkan dengan lengkap atau tidaknya berkas rekam medis disuatu rumah sakit (Alif, 2019).

Kelengkapan EMR merupakan hal yang penting karena berpengaruh terahadap kualitas pelayanan rumah sakit, pengisian data informasi yang tidak lengkap dapat berdampak pada mutu EMR serta pelayanan yang diberikan rumah sakit sehingga dapat memicu terjadinya masalah dimasa yang akan datang (Pratama \& Darnoto, 2017) . 
Fenomena yang sering terjadi berkaitan dengan ketidaklengkapan EMR kurangnya perhatian dokter dan perawat akan penulisan yang spesifik mengenai hasil pemekrisaan yang dilakukan. Keadaan ini akan mengakibatkan dampak bagi intern rumah sakit dan ekstren rumah sakit, karena hasil pengolahan data menjadi dasar pembuatan laporan intern rumah sakit dan laporan ekstern rumah sakit karena laporan ini berkaitan dengan penyusunan berbagai perencanaan rumah sakit, pengambilan keputusan oleh pimpinan khususnya evaluasi pelayanan yang telah diberikan yang diharapkan hasil evaluasinya akan menjadi lebih baik (Frenti Giyana, 2012). Kelengkapan rekam medis sangatlah penting karena akan memengaruhi proses pelayanan atau mempengnaruhi kualitas (Sukma, 2008). Dengan penelitian ini diharapkan pengisian EMR lebih diperhatikan karena terdapat hubungan terhadap mutu rumah sakit.

Berdasarkan telusur data EMR dari seluruh pasien rawat inap periode bulan maret sampai mei 2021 di RS X Bandung terjadi lonjakan kunjungan pasien berobat sehingga menimbulkan masalah dalam pengisian EMR banyak ditemukan data yang tidak diisi. Dilihat dari laporan bulanan dinyatakan kelengkapan EMR masih dibawah target kemenkes $100 \%$ dengan persentase kelengkapan 66,6\% dan angka ketidaklengkapan 33,3\%. Menurut (Maryati et al., 2018) dalam hasil penelitiannya menyebutkan terdapat hubungan antara kelengkapan informasi medis terhadap kekurangan kode diagnosis dalam menjaga mutu. Maka hal tersebut sejalan dengan penelitian ini, dilakukan dengan tujuan agar mengetahui pentingnya rekam medis yang diisi lengkap guna menjaga mutu pelayanan rumah sakit. Diharapkan pengisian EMR lebih diperhatikan karena terdapat hubungan terhadap mutu rumah sakit.

\section{METODE PENELITIAN}

Jenis penelitian yang digunakan analisis kuantitatif dengan pendekatan deskriftif. Populasi pada penelitian ini seluruh data pasien rawat inap RS X Bandung pada bulan Maret sampai Mei 2021 dengan jumlah populasi kunjungan pasien rawat inap yang datang sebanyak 1355 EMR. Untuk penentuan jumlah sampel dalam penelitian ini menggunakan rumus slovin

$$
\begin{aligned}
& \mathrm{n}=\frac{N}{1+N(e)^{2}} \\
& =\frac{1355}{1+(1355)(0.1)^{2}} \\
& =93,1 \approx 93
\end{aligned}
$$

Maka sampel yang digunakan dalam penelitian ini berjumlah 93 EMR. Teknik pengambilan sampel menggunakan random sampling. Random sampling merupakan teknik yang sederhana karena pengambilan sampel dilakukan secara acak tanpa memperhatikan strata yang ada dalam populasi (Sugiyono, 2017). Hasil data analis diolah menggunakan software SPSS versi 26.0 dengan uji stasistik Chi Square. Uji chi square merupakan Teknik statistik yang pada umumnya digunakan untuk menguji sebuah hipotesis sebuah populasi yang berupa nominal dan sampelnya memiliki skala yang besar (Sutisna, 2020).

\section{HASIL DAN PEMBAHASAN}

\section{A. Hasil Penelitian}

Analisis Kelengkapan Pengisian Rekam Medis Elektronik Rawat Inap Guna Meningkatkan Mutu Pelayanan di Rs X Bandung 
Persentase kelengkapan pengisian EMR bulan maret sampai bulan mei 2021. Peneliti mengambil sampel analisis EMR pasien rawat inap RS X Bandung berjumlah 93 EMR.

Tabel 1. Kelengkapan EMR

\begin{tabular}{lcc}
\hline Variabel & \multicolumn{2}{c}{ Kelengkapan EMR } \\
\cline { 2 - 3 } & $\mathbf{N = 9 3}$ & $\mathbf{\%}$ \\
\hline Tidak lengkap & 31 & $33,3 \%$ \\
\hline Lengkap & 62 & $66,6 \%$ \\
\hline Sumber: data primer, 2021 &
\end{tabular}

Berdasarkan hasil pada tabel 1 kelengkapan pengisian EMR rawat inap RS X Bandung yang lengkap sebanyak $62(66,6 \%)$ sedangkan untuk yang tidak lengkap sebanyak $31(33,3 \%)$.

\section{Kekonsistenan dalam Verifikasi CPPT}

Tabel 2 menunjukan bahwa dokter melakukan verifikasi pada CPPT sebanyak 71 (76,3\%) EMR rawat inap sedangkan dokter tidak melakukan verifikasi pada EMR rawat inap sebanyak $22(23,6 \%)$. Terkait verifikasi banyak dokter yang tidak membubuhi tanda tangan elektronik karena kurangnya pemahaman pentinya verifikasi, karena keabsahan penyelenggaraan EMR terletak pada tanda tangan elektronik sebagai bukti autentifikasi terhadap data medis.

Tabel 2. Hasil Uji Chi Square Verifikasi pada CPPT

\begin{tabular}{lccccccc}
\hline \multirow{2}{*}{$\begin{array}{l}\text { Kelengkapan } \\
\text { EMR }\end{array}$} & \multicolumn{2}{c}{$\begin{array}{l}\text { Konsistensi Dokter dalam } \\
\text { Verifikasi CPPT }\end{array}$} & Total & P Value \\
\cline { 2 - 7 } & $\begin{array}{c}\text { Tidak } \\
\text { Tepat }\end{array}$ & \multicolumn{2}{c}{ Tepat } & & & \\
\cline { 2 - 7 } & $\mathbf{N}$ & $\mathbf{\%}$ & $\mathbf{N}$ & $\mathbf{\%}$ & $\mathbf{N}$ & $\mathbf{\%}$ & \\
\hline Tidak lengkap & 22 & 70,9 & 9 & 29,0 & 31 & 100 & 0,001 \\
\hline Lengkap & 0 & 0,0 & 62 & 100 & 62 & 100 & \\
\hline Jumlah & 22 & 23,6 & 71 & 76,3 & 93 & 100 & \\
\hline
\end{tabular}

Sumber: data primer, 2021

Berdasarkan hasil uji chi square pada tabel 2 didapatkan hasil hubungan antara kestabilan dokter dalam verifikasi CPPT terhadap kelengkapan EMR sebesar $p=0,001$ $(\mathrm{p}<0,05)$. Maka kestabilan dokter dalam mengverifiasi CPPT berpengaruh terhadap kualitas EMR rawat inap.

\section{Kekonsistenan pada Deskripsi Diagnosa}

Tabel 3 menunjukan bahwa Masih terdapat dokter yang tidak menuliskan deskripsi diagnosa yang dapat menghambat pengkodean yang akan dilakukan sebanyak 21 EMR yang tidak akurat $(22,5 \%)$ sedangkan $72(77,4 \%)$ EMR rawat inap telah akurat.

Tabel 3. Hasil Uji Chi Square pada Deskripsi Diagnosa

\begin{tabular}{lccccccc}
\hline \multirow{2}{*}{$\begin{array}{c}\text { Kelengkapan } \\
\text { EMR }\end{array}$} & \multicolumn{3}{c}{$\begin{array}{l}\text { Pencatatan Dokter pada } \\
\text { Deskripsi Diagnosa }\end{array}$} & Total & \multirow{2}{*}{ P Value } \\
\cline { 2 - 7 } & $\begin{array}{c}\text { Tidak } \\
\text { Akurat }\end{array}$ & \multicolumn{2}{c}{ Akurat } & & & \\
& $\mathbf{N}$ & $\mathbf{\%}$ & $\mathbf{N}$ & $\mathbf{\%}$ & $\mathbf{N}$ & $\mathbf{\%}$ & \\
\hline Tidak lengkap & 21 & 22,5 & 20 & 64,5 & 31 & 100 & 0,001 \\
\hline Lengkap & 0 & 0,0 & 62 & 100 & 62 & 100 & \\
\hline
\end{tabular}

Analisis Kelengkapan Pengisian Rekam Medis Elektronik Rawat Inap Guna Meningkatkan Mutu Pelayanan di Rs X Bandung 


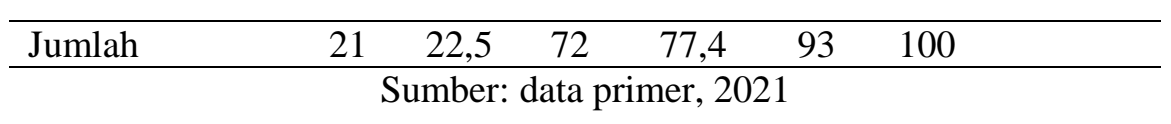

Dari hasil uji chi square pada tabel 3 didapatkan hasil hubungan antara pencatatan dokter pada deskripsi diagnosa terhadap kelengkapan EMR sebesar $p=0,001(p<0,05)$. Maka kekonsistenan pencatatan deskripsi diagnosa yang dilakukan oleh dokter berpengaruh terhadap kualitas EMR rawat inap.

\section{Kekonsistenan pencatatan pada Asesmen Medis}

Kelengkapan asesmen medis dapat mempermudah mengidentifikasi masalah kesehatan pasien jika dikemudian hari berobat kembali namun dapat dilihat pada Tabel 4 menunjukan banyak dokter tidak memperhatikan kelengkapan pencatatan asesmen medis pada EMR rawat inap sebanyak $22(23,6 \%)$, asesmen medis sebanyak $71(76,3 \%)$ EMR rawat inap yang telah lengkap.

Tabel 4. Hasil Uji Chi Square Asesmen Medis

\begin{tabular}{|c|c|c|c|c|c|c|c|}
\hline \multirow[t]{3}{*}{$\begin{array}{c}\text { Kelengkapan } \\
\text { EMR }\end{array}$} & \multicolumn{4}{|c|}{$\begin{array}{c}\text { Pencatatan Asesmen } \\
\text { Medis }\end{array}$} & \multicolumn{2}{|c|}{ Total } & \multirow[t]{3}{*}{ P Value } \\
\hline & \multicolumn{2}{|c|}{ Kosong } & \multicolumn{2}{|c|}{ Ditulis } & & & \\
\hline & $\mathbf{N}$ & $\%$ & $\mathbf{N}$ & $\%$ & $\mathbf{N}$ & $\%$ & \\
\hline Tidak lengkap & 22 & 70,9 & 9 & 29,0 & 31 & 100 & 0,001 \\
\hline Lengkap & 0 & 0,0 & 62 & 100 & 62 & 100 & \\
\hline Jumlah & 22 & 23,6 & 71 & 76,3 & 93 & 100 & \\
\hline
\end{tabular}

Berdasarkan dari hasil uji chi square pada tabel 4 didapatkan hasil hubungan antara pencatatan dokter pada asesmen medis terhadap kelengkapan EMR sebesar $\mathrm{p}=0,001$ $(p<0,05)$. Maka pencatatan dokter pada asesmen medis berpengaruh terhadap kelengkapan EMR rawat inap.

\section{Kekonsistenan pencatatan pada Asesmen Keperawatan}

Tabel 5 menunjukan bahwa perawat melakukan penulisan pada asesmen keperawatan khususnya pada pengisian dischar planning yang rinci sebanyak $86(92,4 \%)$ EMR rawat inap sedangkan sebanyak $7(7,52 \%)$ EMR rawat inap perawat tidak melakukan penulisan pada asesmen keperawatan.

Tabel 5. Hasil Uji Chi Square Asesmen Keperawatan

\begin{tabular}{llllllll}
\hline \multirow{2}{*}{ Kelengkapan } & \multicolumn{3}{l}{ Asesmen Keperawatan } & Total & \multirow{2}{*}{ P Value } \\
\cline { 2 - 7 } & \multicolumn{2}{l}{ Kosong } & \multicolumn{2}{c}{ Ditulis } & & \\
\cline { 2 - 7 } & $\mathbf{N}$ & $\mathbf{\%}$ & $\mathbf{N}$ & $\mathbf{\%}$ & $\mathbf{N}$ & $\mathbf{\%}$ & \\
\hline Tidak lengkap & 7 & 22,5 & 24 & 77,4 & 31 & 100 & 0,001 \\
\hline Lengkap & 0 & 0,0 & 62 & 100 & 62 & 100 & \\
\hline Jumlah & 7 & 7,52 & 86 & 92,4 & 93 & 100 & \\
\hline \multicolumn{7}{c}{ Sumber: data primer, 2021 }
\end{tabular}

Berdasarkan dari hasil uji chi square pada tabel 5 didapatkan hasil hubungan antara pencatatan perawat pada asesmen keperawatan terhadap kelengkapan EMR sebesar $\mathrm{p}=$ $0,001(\mathrm{p}<0,05)$. Maka pencatatan perawat pada asesmen keperawatan berpengaruh terhadap kualitas EMR rawat inap.

\section{Kekonsistenan pencatatan E-Resep}

Analisis Kelengkapan Pengisian Rekam Medis Elektronik Rawat Inap Guna Meningkatkan Mutu Pelayanan di Rs X Bandung 
Terdapatnya keberadaan elektronik resep dapat mempercepat waktu pelayanan, karena penulisanya dilakukan saat pemeriksaan sehingga ketika pelayanan selesai pasien segera membawa obat tanpa menunggu terlalu lama. Dapat dilihat pada tabel 6 menunjukan bahwa persentase e-resep sebanyak 90 (96,7\%) EMR rawat inap hampir mendekati angka target sedangkan e-resep pada EMR rawat inap terlihat kosong sebanyak $3(3,2 \%)$.

Tabel 6. Hasil Uji Chi Square pada E-Resep

\begin{tabular}{|c|c|c|c|c|c|c|c|}
\hline \multirow[t]{3}{*}{$\begin{array}{l}\text { Kelengkapan } \\
\text { EMR }\end{array}$} & \multicolumn{4}{|c|}{$\begin{array}{l}\text { Pencatatan Dokter pada } \\
\text { E-Resep }\end{array}$} & \multirow{2}{*}{\multicolumn{2}{|c|}{ Total }} & \multirow[t]{3}{*}{ P Value } \\
\hline & \multicolumn{2}{|c|}{ Kosong } & \multicolumn{2}{|c|}{ Ditulis } & & & \\
\hline & $\mathrm{N}$ & $\%$ & $\mathrm{~N}$ & $\%$ & $\mathrm{~N}$ & $\%$ & \\
\hline Tidak lengkap & 3 & 9,6 & 28 & 90,3 & 31 & 100 & 0,013 \\
\hline Lengkap & 0 & 0,0 & 62 & 100 & 62 & 100 & \\
\hline Jumlah & 3 & 3,2 & 90 & 96,7 & 93 & 100 & \\
\hline
\end{tabular}

Dari hasil uji chi square pada tabel 6 didapatkan hasil hubungan antara pencatatan dokter pada e-resep terhadap kelengkapan EMR sebesar $p=0,013(p<0,05)$. Maka pencatatan dokter pada e-resep berpengaruh terhadap kualitas EMR rawat inap.

\section{B. Pembahasan}

Berdasarkan hasil penelitian di RS X Bandung belum mencapai target berdasarkan permenkes yaitu $100 \%$ dalam waktu 24 jam setelah selesai pelayanan rawat inap. Didapat tingkat ketidaklengkapan terendah pada e-resep sebanyak 3,2\% sedangkan tertinggi pada verifikasi CPPT dan asesmen medis sebesar 23,6\% sedangkan pada keakuratan diagnosa $22,5 \%$ dikarenakan rendahnya tingkat kesadaran dokter akan pentingnya kelengkapan rekam medis dan juga banyaknya pasien yang berkunjung menyebabkan dokter diharuskan memberi penanganan dengan cepat sehingga dapat mengefektifkan waktu. Dari hasil penelitian analisis kuantitatif yang telah dilakukan memberikan makna bahwa terdapat jumlah perbedaan yang signifikan.

Faktor-faktor yang menyebabkan seringnya diagnosis utama tidak terisi diantaranya waktu dokter yang sempit, pasien yang banyak, pasien APS (atas Permintaan Sendiri), beban kerja yang banyak (dituntut kerja cepat tapi masih ditambah kerja yang lain) (Rohman et al., 2013). Menurut PERMENKES No: 269/MENKES/PER/III/2008 berisi dokter, dokter gigi dan tenaga kesehatan tertentu bertanggung jawab atas catatan dokumen yang dibuat pada rekam medis.

Menurut (Sjamsuhidajat et al., 2006) permasalahan dan kendala utama pada pelaksanaan rekam medis adalah dokter dan dokter gigi tidak menyadari sepenuhnya manfaat dan kegunaan rekam medis, baik pada sarana pelayanan kesehatan maupun pada praktik perorangan, akibatnya rekam medis dibuat tidak lengkap, tidak jelas dan tidak tepat waktu. Kelengkapan rekam medis elektronik tentu sangat berpengaruh terhadap kualitas rumah sakit dalam kesinambungan pelayanan dan keselamatan pada pasien yang berobat. Kelengkapan pengisian berkas rekam medis merupakan suatu penilaian tentang keefektifan suatu rumah sakit. Menurut (Karmila, 2019) ketidaklengkapan juga dapat menghambat proses administrasi dan dapat menyebabkan penolakan verifikator BPJS.

Kemungkinan yang lain apabila rekam medis tidak lengkap akan kesulitan dalam melakukan evaluasi terhadap pelayanan medis yang diberikan kepada pasien dan pada akhirnya tidak dapat dijadikan bukti hukum. Keabsahan rekaman pada dokumen rekam medis yaitu petugas yang bertanggungjawab mengisi berkas rekam medis pasien tersebut diantaranya nama dokter, perawat atau bidan serta tanda tangan dari pemberi pelayanan. Apabila suatu saat terjadi masalah, bukti keabsahan tersebut dapat menjadi alat 
pertanggungjawaban berlandaskan hukum (Alif, 2019). Rekam medis dalam hal ini membantu dalam upaya merumuskan pedoman praktik menangani risiko serta memberikan corak untuk penggunaan pelayanan kesehatan. Dengan memiliki rekam medis yang lengkap membuat pihak manajemen rumah sakit mampu melaksanakan kegiatan menjaga mutu (Wiraja \& Dewi, 2019).

Salah satu cara dalam mewujudkan kepuasan pasien yakni dengan menjaga mutu pelayanan secara berkelanjutan yang dapat dipantau dan berlandaskan pada catatan rekam medis di rumah sakit (Rini et al., 2019). Penyataan (Wirajaya, 2019) ketidaklengkapan dokumen rekam medis menjadi salah satu masalah karena rekam medis merupakan salah satu catatan yang dapat memberi informasi rinci tentang apa yang sudah terjadi selama pasien dirawat di rumah sakit. Hal ini dapat mengakibatkan dampak eksternal dan internal karena hasil pengolahan data menjadi dasar pembuatan laporan baik internal rumah sakit maupun bagi pihak eksternal. Hal ini menunjukkan bahwa pengisian rekam medis masih harus menjadi perhatian utama. Oleh karena itu penting dibuat strategi untuk pemecahan masalah tersebut (Ervavira, 2012). Karena hal tersebut berdampak pada mutu rekam medis serta terhadap pelayanan yang diberikan terhadap rumah sakit (Devhy \& Widana, 2019). Menurut (Simbolon, 2015) untuk mendapatkan predikat akreditasi suatu instansi atau rumah sakit diperlukan rekam medis sebagai salah satu standar yang harus dipenuhi.

Dari hasil uji statistik chi square seluruh variabel yang telah di uji yaitu CPPT, diagnosa, asesmen medis dan asesmen keperawatan memiliki hasil $\mathrm{p}=0,001$ sedangkan pada e-resep $\mathrm{p}=0,013$ dengan taraf kesalahan 0,05 artinya apabila nilai $\mathrm{p}$ value $<0,05$ maka hipotesis nol ditolak dan hipotesis alternatif diterima artinya terdapat pengaruh dari ketidaklengkapan pengisian rekam medis dengan kualitas EMR dengan pelayanan yang dijalankan RS X Bandung.

\section{KESIMPULAN}

Berdasarkan penelitian yang dilakukan, dapat disimpulkan terdapat hubungan pemahaman kepedulian tenaga kesehatan mengenai pengisian EMR terhadap mutu rekam medis dalam pemberi pelayan yang dijalankan rumah sakit. Kelengkapan pengisian EMR RS X Bandung masih rendah dengan hasil 66,6\% EMR yang sudah lengkap pengisiannya dan ketidaklengkapan dengan persentase $33,3 \%$. Hal tersebut karena dokter dan perawat kurang memperhatikan pentingnya rekam medis berperan dalam menjaga kualitas pelayanan rumah sakit. Dapat dilihat hasil kekonsistenan pengisian EMR yang dilakukan dokter pada CPPT dan asesmen medis dengan persentase terendah 76,3\% dan pengisian deskripsi diagnosa $77,4 \%$. Hasil persentase yang rendah menjukkan kualitas EMR belum bisa dikatan baik, karena itu perlunya kebijakan dan pembinaan kepada dokter dalam hal kekonsistenan pengisian EMR mengikuti standar permenkes guna menjaga kualitas EMR ataupun kualitas pelayanan rumah sakit.

\section{BIBLIOGRAFI}

Alif, A. M. (2019). Analisis Kuantitatif Dan Kualitatif Medis Dokumen Rekam Medis Rawat Inap Pasien Asphyxia Neonatorum di Rumah Sakit Daerah Kalisat Periode Januari-Juni. Prosiding RMIK Politeknik Negeri Jember, 2012.

Devhy, N. L. P., \& Widana, A. A. G. (2019). Analisis Kelengkapan Rekam Medis Rawat Inap Rumah Sakit Ganesha Di Kota Gianyar tahun 2019 Completeness Analysis of Inpatien Ganesha Hospital Medical Records in Gianyar City in 2019. Jurnal Rekam Medis Dan Informasi Kesehatan, 2(2). https://doi.org/10.31983/jrmik.v2i2.5353

Ervavira, A. (2012). Perbedaan Kelengkapan Pengisian Rekam Medis Antara Instalasi 
Rawat Jalan dan Instalasi Rawat Darurat di Poli Bedah RSUP DR. Kariadi Semarang. Universitas Dipenogoro.

Frenti Giyana. (2012). Rawat Inap Rumah Sakit Umum Daerah. Kesehatan Masyarakat, $\underline{1 \text { (Analisis sistem pengelolaan rekam medis rawat inap rumah sakit umum daerah }}$ Kota Semarang), 48-61.

Karmila. (2019). Faktor-Faktor Penyebab Ketidaklengkapan Pengisian Dokumen Rekam Medis Pasien Rawat Jalan Berdasarkan Fishbone Diagram DiPuskesmas Jetis Ponogoro. 1-10.

Lubis, E. (2009). Pengaruh Karakteristik Individu dan Motivasi Ekstrinsik Terhadap Kinerja Dokter Dalam Kelengkapan Pengisian Rekam Medis Pasien Rawat Inap di Rumah Sakit PT Perkebunan Nusantara IV (PERSERO) Tahun 2008. Universitas Sumatera Utara.

Maryati, W., Wannay, A. O., \& Suci, D. P. (2018). Hubungan Kelengkapan Informasi Medis dan Keacuratan Kode Diagnosis Diabetes Mellitus. Jurnal Rekam Medis Dan Informasi Kesehatan, 1(2), 96-108. https://doi.org/10.31983/jrmik.v1i2.3852

Pratama, M. H., \& Darnoto, S. (2017). Analisis Strategi Pengembangan Rekam Medis Elektronik Di Instalasi Rawat Jalan Rsud Kota Yogyakarta. Jurnal Manajemen Informasi Kesehatan Indonesia, 5(1), 34. https://doi.org/10.33560/.v5i1.146

Rini, M., Jak, Y., \& Wiyono, T. (2019). Analisis Kelengkapan Pengisian Rekam Medis Rawat Inap Kebidanan RSIA Bunda Aliyah Jakarta Tahun 2019. Jurnal Manajemen Dan Administrasi Rumah Sakit Indonesia, 3(2), 131-142. https://doi.org/10.52643/marsi.v3i2.534

Rohman, H., Hariyono, W., \& Rosyidah, . (2013). Kebijakan Pengisian Diagnosis Utama Dan Keakuratan Kode Diagnosis Pada Rekam Medis Di Rumah Sakit Pku Muhammadiyah Yogyakarta. Jurnal Kesehatan Masyarakat (Journal of Public Health), 5(2). https://doi.org/10.12928/kesmas.v5i2.1082

Simbolon, S. A. (2015). Kajian Yudiris Terhadap Kedudukan Rekam Medis Elektronik Dalam Pembuktian Perkara Pidana Malpraktek Oleh Dokter. Jurnal Lex Crime, 4(6), $152-161$.

Sjamsuhidajat, Alwi, S., \& Rusli, A. (2006). Ma nualre ka mmedis.

Sugiyono. (2017). Metode Penelitian Kuantitatif, Kualitatif dan R\&D. Alfabeta.

Sukma, I. (2008). Faktor Penyebab Ketidaklengkapan Dokumen Rekam Medis Pasien Rawat Inap Dalam Batas Waktu Pelengkapan di Rumah Sakit Umum Daerah Dr.Moewardi Surakarta. Izha Sukma Rahmadhani1, Sri Sugiarsi2, Antik Pujihastuti2, $I I(2), 82-89$.

Sutisna, I. (2020). Statistika penelitian. Universitas Negeri Gorontalo, 1(1), 1-15.

Wiraja, M. K. M., \& Dewi, N. M. U. K. (2019). Analisis Ketidaklengkapan Rekam Medis Pasien Rawat Inap di Rumah Sakit Dharma Kerti Tabanan. Jurnal Administrasi Rumah Sakit, 6(1), 11-20. http://dx.doi.org/10.7454/arsi.v6i1.3553

Wirajaya, M. K. M. (2019). Faktor Faktor yang Mempengaruhi Ketidaklengkapan Rekam Medis Pasien pada Rumah Sakit di Indonesia. Jurnal Manajemen Informasi Kesehatan Indonesia, 7(2), 165. https://doi.org/10.33560/jmiki.v7i2.225

(C) 2021 by the authors. Submitted for possible open access publication under the

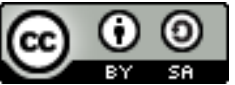
terms and conditions of the Creative Commons Attribution (CC BY SA) license (https://creativecommons.org/licenses/by-sa/4.0/). 